\title{
Dolf Sternbergers Verfassungspatriotismus
}

Dolf Sternberger prägte den Begriff des Verfassungspatriotismus zum 30. Jahrestag der Verabschiedung des Grundgesetzes 1979. Die Verfassung beziehe ihre Rechtmäßigkeit aus Vereinbarung und Übereinkunft der Staatsbürger. Sie sei die Grundlage für das friedliche Zusammenleben und verdiene deshalb Loyalität und Engagement. Patriotismus müsse nicht auf der irrationalen und emotionalen Bindung an eine mythisch verstandene und geschichtlich-kulturell verklärte Nation gründen, sondern er entspringe der Vernunft und Verantwortung der Bürger, das ihnen gegebene Vaterland als Aufgabe zu verstehen. Patriotismus wird so Bekenntnis zur Freiheit der Republik. Sternberger fand seinerzeit mit dem Begriff viel Zustimmung, weil diese Definition der Vaterlandsliebe der politischen Situation und dem damaligen Selbstbewusstsein in der Bundesrepublik entsprach. Nach der Wiedervereinigung mehren sich die Stimmen, die ein „normales“ Nationalbewusstsein und Bekenntnis zum Nationalstaat fordern. Der ideelle Gehalt des Verfassungspatriotismus ist jedoch, unbeschadet seiner interpretationsbedürftigen Bezeichnung, immer noch geeignet, Orientierung für das nationale Selbstverständnis der Deutschen, für den inneren Frieden, den Zusammenhalt und die Zusammenarbeit mit anderen Staaten in der Europäischen Union und in den Vereinten Nationen zu geben.

Inhalt

1. Einleitung

2. Sternbergers Verfassungspatriotismus $\quad 877$

a) Patriotismus und Legitimität

3. Das Grundgesetz als Grund eines demokratischen Patriotismus 886

4. Kritik am Verfassungspatriotismus und die Wiederkehr des Nationalpatriotismus

5. Ausblick

Literatur

898 


\section{Einleitung}

Dolf Sternberger (1907-1989) sprach das Thema der Vaterlandsliebe als Bekenntnis zur Republik erstmalig 1959 in einer Leitglosse der „Frankfurter Allgemeinen Zeitung für Deutschland“ (FAZ) (X, 11 f.) an. ${ }^{1}$ Daran anknüpfend prägte er 1979, zum 30-jährigen Bestehen des Grundgesetzes, am selben Ort in der FAZ (X, 13-16) den Begriff „,Verfassungspatriotismus“. 1982 führte er seine Überlegungen in einer Rede bei der 25-Jahr-Feier der „Akademie für Politische Bildung“ in Tutzing weiter aus (X, 17-19). Der Begriff fand unerwartet viel Zustimmung. Der damalige Bundespräsident Richard von Weizsäcker urteilte dazu: „Der erste ernsthafte Ansatz in der Nachkriegszeit, die Diskussion ausdrücklich beim Stichwort ,Patriotismus" wieder aufzunehmen und voranzubringen, stammt von Dolf Sternberger. [...] Die Frage wird auf den Begriff gebracht, und zwar so prägnant, dass mit der Überschrift bereits die Antwort gegeben wird: Verfassungspatriotismus. Dolf Sternberger hat sich damit ein hohes Verdienst erworben“" (zitiert nach X, 7).

Politiker, Publizisten und Wissenschaftler machten sich den Begriff zu eigen. Die unerwartete Resonanz war eng mit der intellektuellen Entwicklung Deutschlands in den 70er-Jahren verbunden. Norbert Elias stellte damals fest, die Bundesrepublik sei einer der wenigen Staaten Europas, dessen Angehörigen den Zement des Empfindens einer gemeinsamen Identität, wenn man von dem gebrechlichen Stolz auf das Wirtschaftswunder absehe, so gut wie völlig entbehrten (Elias 1992: 545).

Der Boden, auf dem der Begriff des Verfassungspatriotismus zum nationalen Konsens werden konnte, war das Gefühl des Mangels einer eigenen Identität der Bundesrepublik. Einmal sah sich die Bundesrepublik wegen der damals schwindenden Hoffnung auf die Wiedervereinigung und angesichts der nationalen Propaganda des SED-Regimes mit der Frage nach ihrer Identität konfrontiert, zum andern stellte die 1968 beginnende Revolte linker Studenten und Intellektueller ihre freiheitliche Verfassungsordnung infrage. Der Begriff fand auch bei der Frankfurter Schule und der kritischen Linken Zustimmung. Für Jürgen Habermas, der Deutschlands bedingungslose Öffnung zu westlichen Traditionen für die zentrale Errungenschaft der Nachkriegszeit und die in der politischen Kultur verankerten Rechtsprinzipien konstitutiv für die Identität des Gemeinwesens hielt (Behrmann 1993: 20), verkörperte der Verfassungspatriotismus die Gegenposition zu den irrationalen Unterströmungen der deutschen Nationaltradition (Habermas 1995: 17 f.) und zur Tradition der deutschen Nationalgeschichtsschreibung. ${ }^{2}$ „In der kritischen Erziehungswissenschaft ist mehr und mehr verstanden worden, dass die zunächst nur widerwillig hingenommene Festlegung auf die Verfassung auch zu einer Tugend gemacht werden kann. Seitdem sich auch Jürgen Habermas mehrfach zum Verfassungspatriotismus bekannt hat, ist dieser in allen Lagern akzeptiert. Damit ist die intellektuelle Staatsgründung der Bundesrepublik

1 Alle Zitate Sternbergers sind, soweit nichts anderes angegeben, im folgenden als Band und Seitenzahl der Schriften (Sternberger ab 1977) zitiert.

2 Der durch Jürgen Habermas ausgelöste Historikerstreit eskalierte kurz vor dem 80. Geburtstag von Sternberger 1987 (Augstein 1987). 
im Konsens abgeschlossen“ (Behrmann 1999: 496). Der studentische Protest, der sich anfangs der marxistischen Gesellschaftskritik bediente, transformierte sich zu einer Anerkennung nicht des Status quo der Gesellschaft, aber doch der Ordnung des Grundgesetzes, nicht zu einem nationalen, aber doch zu einem demokratischen Patriotismus. ${ }^{3}$

Nach der Wiedervereinigung der Bundesrepublik und der Deutschen Demokratischen Republik und dem Erlangen der vollen Souveränität mehren sich die Stimmen, die auch für die Deutschen ein „,normales“ Bekenntnis zum Nationalstaat und zur nationalen Identität verlangen. ${ }^{4}$ Der „Verfassungspatriotismus“ sei nur ein Notbehelf für das geteilte Deutschland gewesen. Bei dieser Kritik geht es zunächst um das Verständnis der deutschen Geschichte. Für Sternberger, wie auch für Habermas, war der Begriff eine Reaktion auf die Identitätsprobleme der Deutschen nach der deutschen Katastrophe von 1945. Heute stellt sich die Frage nach dem deutschen Selbstverständnis eher im Hinblick auf die weitere Integration Europas und den durch die Immigration entstandenen Multikulturalismus. Es soll daher zunächst geklärt werden, was Sternberger unter Verfassungspatriotismus verstand, und wie sich seine Konzeption von der Habermas'schen unterscheidet.

\section{Sternbergers Verfassungspatriotismus}

Sternberger begann, als er einige Jahre nach seiner Emeritierung mit der Prägung des Begriffs Verfassungspatriotismus „zu meiner Freude eine gewisse Resonanz“ (X, 32) in der Öffentlichkeit gefunden hatte, seine Schriften und Vorträge zu diesem Thema zusammenzustellen. ${ }^{5}$ Es war für den über 70 Jahre alten Wissenschaftler und Publizisten eine Genugtuung, nochmals ein öffentliches Echo zu finden, denn seine wissenschaftlichen Arbeiten hielt die jüngere Politikwissenschaft, zu deren wichtigsten Gründungsvätern er einst gehörte hatte, inzwischen weitgehend für überholt. Nach seinem Tod 1989 wurde

3 So Richard Schröder in der FAZ, 05.03.98, S. 42.

4 Eine detaillierte Darstellung der Problematik gibt Kronenberg 2005. Er bezieht sich allerdings im Wesentlichen auf die öffentliche und wissenschaftliche Debatte und geht nur kursorisch auf die politische Relevanz ein. Bei der geschichtlichen Darstellung des Begriffs werden der Gegensatz zwischen preußischem und nationaldeutschen Patriotismus, der hypertrophe Patriotismus der wilhelminischen Ära und die Rolle des Nationalismus in der Weimarer Republik eher am Rande behandelt.

5 Dass der Verfassungspatriotismus eine späte Frucht Sternberger'schen Schaffens darstellt, zeigt sich daran, dass seine Schüler und Kollegen in der Festschrift zu seinem 70. Geburtstag diesem Aspekt seines Wirkens keine Beachtung schenkten. Haungs erwähnt nur Sternbergers in seinem publizistischen Wirken sich äußerndes Engagement zur politischen Erziehung und seine Forderung an den aktiven Bürger, im Verfassungsstaat mitzuarbeiten (1977: 18 f.). Hennis referiert Sternbergers Auffassung von der Verfassung, die es mit vernünftigem und verfassungsmäßigen Leben auszufüllen gelte (1977: 172). Auch in der Würdigung des Bundespräsidenten von Weizsäcker wird darauf hingewiesen, dass in seinem reichem wissenschaftlichen und publizistischen Wirken das Thema nur einen schmalen Raum einnimmt (X, 7). 
diese von ihm vorbereitete Sammlung als 10. Band seiner Schriften mit dem Titel „Verfassungspatriotismus“ von Peter Haungs, Klaus Landfried, Elsbet Orth und Bernhard Vogel herausgegeben.

Sternberger hat sich zu dem Begriff „Verfassungspatriotismus“ explizit nur in Reden, Essays und Leitglossen geäußert. Seine Konzeption und Einsichten wurden assoziativ und interpretierend entwickelt (Gebhardt 1999: 21). Manche Ausführungen wirken auch eher als nachgeschobene Begründungen und sind nicht durch ein eingehendes Studium der Quellen belegt. Zur Klärung der Frage, wie der Begriff entstand, ist es deshalb unerlässlich, nicht nur seine Schriften zum Verfassungspatriotismus zu lesen, sondern auch die in seinen anderen politischen Schriften entwickelten Gedanken zu Gestalt und Gestaltung der Republik zu berücksichtigen.

Bereits im Jahr 1947 veröffentlichte Sternberger einen Essay über den Begriff des „Vaterlandes“ in der „Wandlung“, einer unter Mitwirkung von Karl Jaspers, Werner Krauss und Alfred Weber von ihm herausgegebenen, damals viel beachteten Stimme zum geistigen Wiederaufbau Deutschlands. ${ }^{6}$ Das war in dem noch von Not, Zerstörung und Unsicherheit über die Zukunft, aber auch von Schuldgefühlen gezeichneten dritten Nachkriegsjahr, zwei Jahre vor der Verabschiedung des Grundgesetzes, ein mutiger und optimistischer Diskussionsbeitrag. Sternberger reflektiert in diesem Essay die Konsequenzen, die sich aus den Gräueltaten des nationalsozialistischen Systems, aus dem Zusammenbruch Deutschlands und dem millionenfachen Tod für das Vaterland ergeben. Noch aber war nicht sicher, ob und wie Deutschland wieder als souveräner Staat aus den Ruinen auferstehen würde.

Die Sprache, die Sternberger hierbei und auch später bei der Begründung des „Verfassungspatriotismus" verwendet, klingt heute pathetisch und emotional. Darin zeigt sich jedoch, dass er für die staatliche und nationale Identität des neuen Deutschland nicht nur eine in die Zukunft gerichtete rationale, sondern vor allem auch eine emotionale Grundlage zu schaffen suchte. Der Neubeginn konnte nur mit einer freiheitlichen Verfassung gelingen: „Der Begriff des Vaterlandes erfüllt sich erst in seiner freien Verfassung - nicht bloß in seiner geschriebenen, sondern in der lebenden Verfassung, in der wir alle uns als Bürger dieses Landes befinden, an der wir täglich teilnehmen und weiterbilden. Das Vaterland ruft jeden Tag, denn jeden Tag müssen und wollen wir darin leben, miteinander leben“ (IV, 33). In diesen Sätzen ist der Kerngedanke des Verfassungspatriotismus enthalten, den er Jahrzehnte später ausführlicher begründet, aber nicht mehr ändert.

Die Liebe zum Vaterland, der Patriotismus, beziehe sich auf die konkrete, tägliche Gestalt der von Bürgern getragenen Republik, nicht auf ein imaginiertes Kollektiv. Das die Freiheit schaffende Vaterland werde gestaltet im Rahmen der Verfassung und zwar nicht nur der geschriebenen, sondern der durch die Bürger mitgetragenen und geprägten ,le-

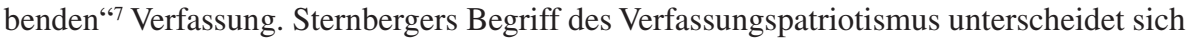
damit so grundsätzlich von den historischen Ausprägungen des Patriotismus zwischen

6 Die Wandlung 2 (6), 1947, wieder abgedruckt in: IV, 9-34.

7 Nach dem Titel seines Buches „Lebende Verfassung“ (Sternberger 1956). An anderen Stellen seiner Schriften spricht er von „lebendiger" Verfassung. Beide Begriffe werden synonym verwandt. 
1750 und 1933, wie der moderne Verfassungsstaat von den staatlichen Formen der Vergangenheit. Er hat wenig gemein mit dem Adelspatriotismus des 18. Jahrhunderts, dem romantischen und liberal-demokratischen Patriotismus des im 19. Jahrhundert entstehenden Nationalstaats und dem revanchistischen Patriotismus der rechten Parteien in der von inneren Auseinandersetzungen zerrissenen Weimarer Republik. Sternberger reflektiert zwar die Ideengeschichte, aber letztlich nur, um die Unterschiede zu seiner Konzeption herauszuarbeiten oder auf die Übereinstimmung mit den früheren Staatsdenkern hinzuweisen, nicht aber, um die Ausprägungen des Patriotismus historisch und systematisch abzuhandeln.

$\mathrm{Zu}$ Erläuterung seines Vorgehens kann dazu sein Rekurs auf den Schriftsteller Thomas Abbt (1738 - 1766) dienen. Dieser bemühte sich, angesichts des damals in Europa entstehenden bürgerlichen Patriotismus zu begründen, dass man auch in Monarchien, konkret im friderizianischen Preußen, das Vaterland lieben könne. Sternberger sieht darin eine Instrumentalisierung von Gefühlen, die nur demokratischen, republikanischen und bürgerlichen Einrichtungen und Gesetzen zukämen. Er hielt Abbt für einen frühen Protagonisten einer auf den Monarchen und das Heer, das in Preußen die Stelle der bürgerlichen Republik vertreten habe, bezogenen perversen Konzeption eines Patriotismus, in der die Obrigkeit patriotische Gefühle ohne die republikanischen Einrichtungen zu erwecken und ein Gewohnheitsethos des soldatischen Menschen zu prägen suche. Dieser Idee seien viele arglos gefolgt, viele auch für sie gestorben und schließlich hätte dieser Patriotismus zu den verruchten Zwecken der Despotie missbraucht werden können (IV, 28-30). 32 Jahre später erwähnt er Abbt erneut, diesmal als einen ,glänzenden Schriftsteller“8. Abbt ist nunmehr für ihn ein Kronzeuge dafür, dass sich der Patriotismus immer nur auf den konkret vorhandenen Staat beziehen könne, nicht auf ein imaginiertes Kollektiv, wie das Volk oder die Nation (X, 22).

Die Auffassung, dass Patriotismus sich nur auf den republikanischen Staat als Gemeinschaft der Bürger beziehen könne, durchzieht seine gesamten politischen Schriften. Weil die deutsche Geschichte kein Vorbild für den neuen Staat bereit halte, sei die Rückbesinnung auf die klassische Staatslehre von Aristoteles und Montesquieu und die Orientierung an der Idee eines werteerfüllten, freiheitlichen Gemeinwesens, wie sie in der amerikanischen Verfassung und im englischen Parlamentarismus zum Ausdruck komme, angezeigt. Es gehe darum, im neuen Deutschland das „Glück und die Pflicht“ am gemeinsamen Wesen des Staates im Sinne der Vaterlandsliebe zu erwecken: „Das Vaterland ist die ,Republik', die wir uns schaffen. Das Vaterland ist die Verfassung, die wir lebendig machen“. ${ }^{9}$ „Das Vaterland ist die Freiheit, deren wir uns nur wahrhaft erfreuen, wenn wir

8 Diese mehrdeutige Stelle bestärkte Behrmann (1993: 8) in seiner Kritik, der Verfassungspatriotismus sei sozial, räumlich und geschichtlich indifferent. Sie wird der Argumentation Sternbergers jedoch nicht gerecht.

9 In einer Auseinandersetzung mit der Kritik, die Sternbergers Lehrer Karl Jaspers an der Bundesrepublik äußerte, sah er doch die Gemeinsamkeit im Grundsätzlichen: „Auf den Sinn der Bürger für die Unantastbarkeit der Verfassung möchte Karl Jaspers den Staat gegründet wissen. Wahrhaftig nirgend anders entspringt die Quelle der Rechtmäßigkeit wie der Lebenskraft des Staatswesens (IV, 169). 
sie selber fördern, nutzen und bewachen“ (X, 12). „Der Begriff des Vaterlandes erfüllt sich erst in seiner freien Verfassung - nicht bloß in seiner geschriebenen, sondern in der lebenden Verfassung -, in der wir alle uns als Bürger dieses Landes befinden, an der wir täglich teilnehmen und weiterbilden. Das Vaterland ruft jeden Tag, denn jeden Tag müssen und wollen wir darin leben, miteinander leben“. Die Freiheitlichkeit der Verfassung eines Staates zeigt sich für Sternberger nicht nur in den in ihr verankerten Grundrechten, sondern auch in einem adäquaten Regelwerk der Entscheidungsprozesse, im extrakonstitutionellen politischen Betrieb und im politischen Stil.

Die Essenz seiner Anschauungen ist der streng und ausschließlich auf den Staat bezogene Vaterlandsbegriff $(X, 22)$. Der Staat, dem die Liebe des Bürgers gebührt, ist der Verfassungsstaat, der die Freiheit sichert wie - diese beiden Beispiele nennt Sternberger - in der Schweiz und in den USA (X, 30). Darüber wollte er zwar die Bedeutung anderer Gemeinsamkeiten nicht verneinen, wie die geschichtliche Überlieferung, die ausgebildete Sprachkultur und das gemeinsame, etwa in den Leiden des Krieges und der Vertreibung erfahrene Schicksal. In der Verfassung sah er jedoch den eigentlichen Kern des Nationalstaates (X, 30 f.). Der Begriff des Verfassungspatriotismus war für ihn kein Ersatz eines nationalen Patriotismus, kein Notbehelf für das westliche Nachkriegsdeutschland, sondern er beinhalte, was der Patriotismus in Europa immer ursprünglich und wesentlich gewesen sei $(X, 32)$.

Die Bürger lieben das Vaterland, weil es ihnen zugehört, weil sie es mitgestalten. Sie lieben es nicht wegen der geschehenen Geschichte, an der sie nichts mehr ändern können, deren Gedächtnis sie mit sich führen und an deren Erbteil sie tragen, wie gerne sie möglicherweise auch frei davon wären, sondern sie lieben das Vaterland, dessen Geschichte sie gestalten wollen (IV, 231), weil alle gesellschaftliche Verbesserung von der politischen Verfassung abhängt (IV, 227). Der Bezug auf den politisch handelnden und gestaltenden Staat unterscheidet den Patriotismus von der Heimatliebe. ${ }^{10}$ Die Ineinssetzung von Heimat und Vaterland verkenne die essentielle Begründung des Patriotismus als Bekenntnis zur Freiheit und zur Republik. ${ }^{11}$ „Indem wir den Begriff des Vaterlandes zu gewinnen trachten, fragen wir immerfort auch danach, welches Verhältnis wir selbst zum Vaterlande einnehmen, streben wir fortwährend danach, in das rechte Verhältnis zum Vaterland zu kommen. Sowohl das gültige Rechtsverhältnis suchen wir wie auch das gebotene oder erlaubte, das angemessene Gefühlsverhältnis. Es ist nicht das Verhältnis der wachsenden und verwelkenden Pflanze zu dem Boden, der sie trägt und nährt; es ist nicht das Verhältnis des unmündigen Kindes zum Vater als Zuchtmeister; es ist auch nicht das Verhältnis des Untertans zur Obrigkeit, die Gewalt über ihn hat, und weil sie Gewalt über ihn hätte -

10 Diese Unterscheidung wird vor allem im ersten Essay zur Vaterlandsliebe (IV, 13 f.) begründet: „Heimat ist, wovon wir ausgehen", sie ist gegeben. Gegeben ist auch das Vaterland, aber das naturhaftselbstverständliche Element im Begriff des Vaterlandes darf nicht überschätzt werden, es ist uns ,,aufgegeben“.

11 Dagegen Kronenberg (2005: 24), der im Bezug auf die Verschwörung des 20. Juli 1944 meint, diese Ineinssetzung, die „Treue zur Heimat, die politisch ihre Physiognomie in der Nation findet“, habe gerade das moralische Dilemma der Verschwörer des 20. Juli 1944 ausgemacht. 
deswegen nicht, weil das Vaterland ja gerade das Gemeinsame, das gemeinsame Feld und die gemeinsame Aufgabe seiner Angehörigen sein sollte und weil es darin nicht Obrigkeit und Untertan, kein Oben und Unten geben kann" (IV, 21 f). Nur eine freie, freiwillige Anhänglichkeit kann das rechte Gefühlsverhältnis des Einzelnen zu seinem Vaterland, nur eine bürgerliche Verfassung kann eine vaterländische Verfassung sein. Sternberger beruft sich hierfür auf Montesquieu - aus seiner Sicht der eigentlich moderne Klassiker der Politik -, der mit aller Schärfe und Klarheit die Vaterlandsliebe einzig der republikanischen Verfassung zugeordnet und zugeschrieben habe.

\section{a) Patriotismus und Legitimität}

In den Wiederaufbaujahren der Bundesrepublik hatten Friedrich Meineckes Ansichten zur „Kulturnation“ und seine Begründung des „,echten Vaterlandgefühls“" großes Gewicht. ${ }^{12}$ Inhaltlich deckt sich Sternbergers Bestimmung des Patriotismus weitgehend mit der Meineckes, gegenüber dessen historisierender Herleitung begründet er den Patriotismus jedoch auf eine staatstheoretische Argumentation.

Im Normalfall beruhe staatliche Herrschaft auf Gehorsam durch Gewöhnung und Zwang (VII, 127-229). Jedwede Herrschaft benötige aber darüber hinaus Anerkennung und Zustimmung. Wenn die staatlichen Machthaber dieser nicht kraft ihres Herkommens oder aufgrund traditioneller und ideologischer Begründung sicher sein könnten, suchten sie die Zustimmung der Bevölkerung oder zumindest der staatstragenden Elite durch Erweckung eines Zugehörigkeitsgefühls im Nachhinein zu gewinnen (VII, 20). Auch absolutistische Monarchien strebten danach, im Zeichen der Individualisierung und Rationalisierung durch die Aufklärung, wie schon bei Thomas Abbt gezeigt, die „Liebe“ ihrer

12 Meinecke wird oft für ein der westeuropäischen Idee der Staatsnation entgegengesetztes, vor allem in Deutschland und Osteuropa vorherrschendes Verständnis der Nation als „Kulturnation“ (Meinecke 1963) in Anspruch genommen. Dabei wird allerdings zumeist verkannt, dass für ihn die „Kulturnation" sich durch die Verwirklichung der Werte der frühen deutschen Nationalbewegung definierte. Diese habe in der Einigung der Nation die Voraussetzung für die Entfaltung der Freiheit gesehen. Die demokratischen Verfassung, durch die das größte Maß von innerer Freiheit für die Einzelpersönlichkeit gegeben sei, sei das unwiderrufliche Ergebnis der geschichtlichen Entwicklung Deutschlands, sie bilde den Abschluss einer Entfaltung zum gemeinschaftlich von allen Bürgern getragenen Staat. Meinecke geißelte den radikalen Nationalismus des wilhelminischen Bürgertums als Irrtum und Illusion. Echtes Vaterlandsgefühl habe nichts mit Nationalismus und einem exklusiven und intoleranten ,Nationalstolz“ zu tun. Nation und Nationalismus seien Ergebnis der historischen Entwicklung, Nation sei nicht eine politisch entscheidende Kategorie. In einem seiner letzten Aufsätze meinte er 1949, nach den schlimmen Erfahrungen mit dem Nationalismus in den ersten Jahrzehnten des Jahrhunderts, dem Nationalsozialismus und der neuen Bedrohung durch die Sowjetunion könne es die höchste und weiseste Staatsräson sein, wenn die Staatsräson des europäischen Einzelstaats in der allgemeinen Staatsräson Europas aufgehe (dazu Meinecke 1968: 84 ff., 95, 280 f., 493). Eine genaue Analyse zeigt, dass Meinecke, obschon geprägt von der deutschen Romantik, die Nation in erster Linie als eine ideelle Gemeinschaft verstanden und damit die Vorstellung der Nation als imaginierter und konstruierter Gemeinschaft in gewisser Weise vorweg genommen hat (Koch 2005: 439). 
Untertanen zu erlangen. Die im 20. Jahrhundert entstandenen autoritären und totalitären Regime zeigten zur Festigung ihrer Herrschaft sogar eine wahre Gier nach Zustimmung, um damit ihren inneren Zusammenhalt zu stärken (VII, 81).

Nur rechtmäßig regierte Staaten können nach Sternberger die Anhänglichkeit, Zuneigung und Loyalität der Bürger beanspruchen. Der Staat verdiene diese nicht deshalb, weil die Bürger in ihn hineingeboren seien und weil sie ihm nicht entrinnen könnten, also weil er Schicksalsgemeinschaft sei. Jedwede Form des Patriotismus sei vielmehr mit der Frage nach der Legitimität der Herrschaft verbunden, der Patriotismus könne nicht indifferent gegenüber der Legitimität oder dem Grund der Macht sein. Erst durch eine republikanische Verfassung und das darauf gründende Zugehörigkeitsgefühl der Bürger werde der Staat zum Vaterland. Dies bedeute auch, dass es ohne Staat kein Vaterland geben könne. Für Sternberger ist der Staat, der die Vaterlandsliebe einfordern kann, eine historisch entstandene Herrschaftsorganisation, die sich durch eine freiheitliche, republikanische Verfassung auszeichnet. Kulturelle, sprachliche oder religiöse Gemeinsamkeiten seien dafür sekundär, die durch die Verfassung gegebene staatliche Ordnung ist der primäre Grund für Loyalität und Patriotismus.

Obschon der deutschen Kultur und Sprache zutiefst verbunden, vertritt Sternberger die reine Auffassung der „Staatsnation“. Für ihn ist das Vaterland nicht die Heimstatt einer Nation, die als ein ,dunkles, mythisches und mystisches Wesen, worin alle Personalität, alle individuelle Freiheit, versänke“, verstanden wird (X, 22). „Das Vaterland ist gerade nicht der dunkle, undurchdringliche Mutterschoß, als welchen Leopold Ranke, in einer Art konservativer Mystik, die Nationalität verstand - oder vielmehr dem Verstand entzog“ (IV, 20). Ranke und die sich ihm anschließende deutsche Nationalgeschichtsschreibung beeinflussen dagegen immer noch das Denken der Befürworter des neuen „Nationalen Patriotismus". 13

Die Resonanz von Sternbergers Verfassungspatriotismus entspricht der Zäsur des ,,annum mirabilis“ 1983 der deutschen Geschichtsschreibung, mit der die Dominanz eines auf dem Essentialismus historischer Phänomene beruhenden Nationalismusbegriffs aufgelöst worden sei. Nationale Identität wird seither als Konstrukt des menschlichen Geistes und seiner Kategorien erkannt (Wehler 2001: 8-13). ${ }^{14}$ Damit wird ein Legitimationsmuster infrage gestellt, das die Nation als Legitimationsspender unter Berufung auf historische Traditionen, naturrechtliche Ideen oder eine geschichtliche Bestimmung verstand. Die so definierte Nation konnte die Loyalität ihrer Angehörigen einfordern, weil die Legitimität des auf sie gründenden Nationalstaats durch Geschichte, Herrschaftstradition, Schicksalsgemeinschaft, Kulturgemeinschaft oder die Vorstellung einer weltgeschichtlichen Mission vorgegeben war.

13 Der Begriff „Nationaler Patriotismus“ als Gegenbegriff zum „Verfassungspatriotismus“ ist neuerdings in der Fachliteratur üblich geworden, so auch bei Kronenberg (2005: 36-39, 202).

14 Diese Zäsur durch die konstruktivistische Auffassung von Nation ist allerdings nur eine Wiederaufnahme früherer konstruktivistischer Ansätze, wie sie u. a. aufgrund der neukantianischen Erkenntnistheorie schon Max Weber in den Kapiteln II, 3 und III, 3 von Wirtschaft und Gesellschaft entwickelte (Wehler 2001: 9). Siehe auch Radkau 2005: 533. 
Der von Sternberger geprägte Begriff des Verfassungspatriotismus muss als das Bemühen verstanden werden, gegen ein national-essentialistisches ein neues staatsbürgerliches Legitimationsmuster zu setzen. Nur der demokratische Verfassungsstaat könne die Loyalität der Bürger beanspruchen. Was aber begründet dessen Legitimität? Sternberger entwickelt in seinen Büchern „Grund und Abgrund der Macht“ (VII) und „Drei Wurzeln der Politik“ (II) sowie in den Essays in „Herrschaft und Vereinbarung“ (III), „Staatsfreundschaft" (IV) und „Verfassungspatriotismus“ (X) eine Antwort, die das abendländische Staatsdenken mit den geschichtlichen Ausprägungen des westlichen Staates und den Erfahrungen mit den Verirrungen des Nationalismus verbindet. Allerdings gäbe es auf die universelle Frage nach dem Grund der Regierungsmacht keine allgemeinverbindliche politikwissenschaftliche, ideengeschichtliche oder verfassungstheoretische Antwort. Die Frage nach dem Grund von Legitimität möge am ehesten als eine philosophische Frage gelten (VII, 14).

Dabei steht im Vordergrund seiner Ausführungen die in den 50- und 60er-Jahren in den Heidelberger Sozialwissenschaften besonders intensive Auseinandersetzung mit Carl Schmitt und Max Weber. Sternberger stellte seine Auffassung vom Wesen der Politik, auf der sein Verfassungspatriotismus gründet, in seiner Heidelberger Antrittsvorlesung vor, deren Titel „Begriff des Politischen“ (IV, 295-320) identisch ist mit der kontroversen Abhandlung Carl Schmitts aus dem Jahr 1932 (Schmitt 1963). Gegenüber dessen ,geistesgeschichtlicher" Betrachtungsweise, mit ihrer Versessenheit auf Doktrinen und Theoreme ${ }^{15}$, stellt er seine phänomenologische, die sich konkret der Verfassungsentwicklung zuwende. An der Ausbildung der parlamentarischen Regierungsform seien viele vitale Gründe, wie Triebe, Ideen, Interessen und Prinzipien, beteiligt und diese seien stets miteinander verknüpft, ohne dass man, „marxistisch gesprochen“16, immer einen Unterbau und Überbau unterscheiden könne. Eine interessengeschichtliche und materialistische Betrachtung verfälsche diese Erkenntnis ebenso wie Carl Schmitts Theorem, die politischen Handlungen und Motive seien auf die Unterscheidung von Freund und Feind zurückzuführen und aus dieser Dichotomie sei das Ideal des absoluten, souveränen, zentral regierten und verwalteten Staates, der den Bürgerkrieg beende und damit Frieden schaffe, abzuleiten (IV, 315).

Auch die wertfreie Herrschaftssoziologie Max Webers biete keinen geeigneten Ansatz. ${ }^{17}$ Inhaltlich und methodisch befriedige die nur beschreibende und vergleichende Untersuchung der Legitimitätsarten und die Ausbildung von Idealtypen nicht, denn die Wissenschaft müsse auch die Fundamente, auf welchen die Rechtmäßigkeit westlicher, verfassungsmäßiger Regierungen ruhe, kritisch prüfen. Die wissenschaftlich neutrale und objektive, auf die Formen der Herrschaft und Gehorsamserzwingung konzentrierte Beschreibung der Legitimitätsarten reiche dazu allein nicht aus (VII, 227). Wenn Wissen-

15 VII, 283. Er sah Schmitts Denken in den Bahnen der Machtpolitik Treitschkes und bestimmt von der Verweigerung ethischer Fragen der Politik (IV, 163).

16 Die Denkform Marx'scher Provenienz, die Sternberger bei Schmitt konstatiert, bestimmt nach Wehler auch die Verfechter eines essentialistischen Nationalismus: „Die vorgegebene politische und sprachliche ,Basis“ der Nation generiert einen ideellen ,Überbau“ in Gestalt des Nationalismus“ (Wehler 2001: 8).

17 Wenngleich er an den ,großen Max Weber“ (Sternberger 1997: 97) z. B. bei der Dekonstruktion historischer Phänomene wie auch in zahlreichen anderen Bezügen anknüpft. 
schaft die Aufgabe habe, ein menschliches oder gesellschaftliches Phänomen in seiner Vollständigkeit zu begreifen, so müsse sie mehr leisten, als Symptome zu beschreiben. Sie müsse nach den Ursprüngen und nach dem Sinn forschen. Wenn gesicherte wissenschaftliche Methoden dafür nicht ausreichten, so möge sie gezwungen sein, die Grenzen zu überschreiten, die die Methodik gezogen habe, und in die Sphäre der Philosophie einzutreten, d. h. das bloße „Verstehen“ zu verlassen und das „Urteil“ zu wagen (III, 142-143).

Sternberger wendet sich auch gegen die „Blindheit“ Max Webers gegenüber den genossenschaftlichen und bürgerlichen Regierungsformen mit ihrer eigentümlichen Rechtmäßigkeit sowie gegenüber Wahl und Plebiszit. Weber verkenne den Gegensatz zwischen vertraglicher und herrschaftlicher Ordnung. ${ }^{18}$ Eine ursprünglich demokratische Legitimität sei in dessen Typologie nicht vorgesehen (III, 145). Zwar habe er als erster das Element der Legitimität politischer Herrschaft kenntlich gemacht, seine Typenlehre sei aber „psychologistisch“. Sternberger setzt Webers Typologie eine andere entgegen, die nach dem Grund der Legitimität frage ${ }^{19}$, indem er idealtypisch drei Legitimitätsgründe, den numinosen Grund, den faktischen Grund und die bürgerliche „Vereinbarung“ unterscheidet. In der letzteren Art von Legitimität sieht Sternberger das Legitimationsmuster des demokratischen Staates. Die westlichen Staaten, welche die Elemente der Wahl und der Repräsentation in ihren Verfassungen verbänden, verwirklichten es am besten. Diese seien nicht aus einem einzigen Prinzip konstruiert, nicht Erzeugnis philosophischer oder juristischer Ableitung, sondern das Ergebnis eines Ringens geschichtlicher und gesellschaftlicher Kräfte, ein System von Normen und Spielregeln, entstanden aus einem Friedenschluss der gesellschaftlichen Kräfte (VII, 233). Gegen das Element der Wahl, das Legitimation verleiht, sei zwar die Skepsis Max Webers ${ }^{20}$ angebracht. Wenn man aber das Element der

18 Sternberger sieht bei Max Weber ein „,seltsam trotzig-bitteres Pathos der Desillusionierung“, das diesen zur Überzeugung gebracht habe, freie Pakte seien nur Schein und Selbstbetrug, das Eigentliche sei überall der Zwang, also die Herrschaft (IV, 313). Inzwischen hat Edith Hanke in ihrer werkgeschichtlichen Studie zur Herrschaftssoziologie auf das Schwanken Max Webers, entweder die demokratische Legitimität vom Plebiszit über die Qualität der Führerschaft, sozusagen als Unterform charismatischer Legitimität, her zu verstehen, oder sie als einen eigenständigen vierten Typ legitimer Herrschaft durch Willensäußerung der Beherrschten zu identifizieren, hingewiesen (Hanke/Mommsen 2001: 42). Dies veranlasst Hans Boldt (Hanke/Mommsen 2001: 165) zu der Frage, ob dies nicht ein Hinweis sein könnte, dass Weber selbst das Defizitäre an seiner Systematik erkannt habe. Weber hat den Schritt zu einer liberal-demokratischen Legitimitätsbegründung staatlicher Herrschaft, etwa im Anschluss an die klassische Staatsvertragslehre, nicht getan.

19 Der „Glaube“ sei nicht nötig für eine legitime Regierungsweise: „Diejenigen Regierungen, die aus Wahlen hervorgehen und diejenigen Verfassungen, die auf bürgerlicher Vereinbarung gegründet sind, verlangen keinen Glauben. Ihre Rechtmäßigkeit fußt auf dem Selbstvertrauen des Menschen, auf der Einsicht in die gesellige, bürgerliche, politische Natur des Menschen, oder, wenn man will, auf dem freien Entschluss zum Staat und auf der Kraft zu einem solchen Entschluss“" (VII, 362).

20 Max Weber, der sich in erster Linie für die Legitimitätsbeziehung zwischen Herr und Verwaltungsstab und nur am Rande für Legitimitätsvorstellung der Beherrschten interessiert, nimmt für die Masse der Wähler im Alltagsfall eine Prädominanz äußerlicher Anpassung durch Gewohnheit und materielle Interessen an die gegebene Macht an. Im Außeralltäglichen neigt die Masse dagegen eher zu Emotionalität und Anerkennung der charismatischen Herrschaft (Breuer 1997: 118). 
Wahl mit dem Element der Repräsentation, welches die Führung des Staates ermöglicht, verbinde, gelange man zur besten, zur gemischten Verfassung ${ }^{21}$, d. h. zur demokratischoligarchischen Doppelnatur des modernen parlamentarischen Verfassungsstaates (VII, $11)^{22}$. Der parlamentarische Verfassungsstaat sei weder schiere Demokratie noch schieres repräsentativ-oligarchisches System (VII, 352). Auch seine Regierung erteilt Befehle und übt Zwang aus, aber sie tut es vermöge einer fundamentalen Vereinbarung, der Verfassung. Deshalb „herrscht“ eine parlamentarische Regierung nicht über Menschen. Wo immer sie in Herrschaft übergehe, büße sie ihre bürgerliche Rechtmäßigkeit unweigerlich ein. Die republikanische Legitimität hafte eben nicht an der Herrschaft, sondern an der Vereinbarung, an der Übereinkunft (III, 131).

Gegen das Legitimationsmuster Sternbergers gibt es grundsätzliche Einwendungen. Aus demokratietheoretischer Sicht sei das Modell der gemischten Verfassung konservativautoritär. ${ }^{23}$ Kielmansegg wandte dagegen ein, dass zwar Vereinbarung zur Bedingung der Möglichkeit legitimer Herrschaftsausübung gemacht werden könne, aber dass sie es ist, lasse sich letztlich nie aus der Vereinbarung herleiten (1997). Zu diesem Einwand muss nochmals darauf hingewiesen werden, dass es sich bei Sternbergers Legitimationsmuster, wie er selbst urteilt, um eine philosophisch begründete Norm handelt, die einem anthropologischen Ansatz verpflichtet ist und die die westliche, ,abendländische“ Tradition in Anspruch nimmt. Er sieht die republikanische Legitimität in Konkurrenz zu anderen möglichen und faktischen Legitimationsmustern. Es geht ihm nicht um die Beschreibung eines ,Ist"-Zustandes, sondern um die Norm, deren Erfüllung erst Patriotismus ermögliche.

21 Gerade in der gemischten Verfassung sieht Schmitt die Verderbnis, denn „die wunderbare Armatur einer modernen staatlichen Organisation erfordert einen einheitlichen Willen und einen einheitlichen Geist. Wenn mehrere verschiedenartige, miteinander streitende Geister aus dem Dunkeln heraus diese Armatur bewegen, wird die Maschine bald zerbrechen und mit ihr das System einer gesetzesstaatlichen Legalität" (Schmitt 1938: 118).

22 In der Anerkennung der parlamentarischen Demokratie als beste „gemischte Verfassung“ stimmte er jedoch, wenn auch mit der dargelegten anderen Begründung, wieder mit Max Weber überein. Sternbergers Vorstellung von der „gemischten Verfassung“ geht auf Aristoteles zurück und er nennt sie deshalb altertümlich „Politie“ (VII, 330).

23 Lietzmann (1999: 263) rechnet Sternberger, Alexander Rüstow und Carl-Joachim Friedrich einer Schule des konservativen Konstitutionalismus zu, der die Schwächen der Mehrheitsdemokratie moderner Prägung zu konterkarieren suche. In einer früheren Arbeit (Lietzmann 1993: 46) sieht er dieses, in der Tradition Max und Alfred Webers und Josef Schumpeters stehende, elitistische politische Führungsmuster als ein spezifisches Mischungsverhältnis der autoritären Staatswissenschaft des 19. Jahrhunderts mit Elementen einer republikanischen, gemeinschaftsorientierten Grundhaltung. Diese Interpretation geht an der Argumentation Sternbergers, der sich gerade vom Konstitutionalismus distanziert, vorbei. 


\section{Das Grundgesetz als Grund eines demokratischen Patriotismus}

Für sein Konzept des Verfassungspatriotismus gäbe es gerade in Deutschland gute Gründe. Das Verhältnis des Bürgers zum konkreten Staat sei immer abhängig von der jeweiligen historischen Lage. So war der deutsche Patriotismus im 19. Jahrhundert bestimmt von dem Verlangen nach der bürgerlichen Teilhabe im monarchisch regierten Staat, vom Streben nach nationaler Selbstbestimmung aufgrund der Erfahrungen der napoleonischen Fremdherrschaft und vom Wunsch nach Überwindung der Kleinstaaterei des Deutschen Bundes durch die nationale Einigung. Sternbergers Appell für einen Verfassungspatriotismus ist geprägt von den persönlich erlebten Erfahrungen des Scheiterns der Weimarer Republik und dem Unheil der nationalsozialistischen Despotie, den schwierigen Jahren des Aufbaus der neuen Demokratie, ihrer inneren Gefährdung durch eine autoritäre Restauration sowie der Bedrohung durch den Sowjetkommunismus.

Ihn trieb in den Jahren nach dem Zusammenbruch von 1945 die Sorge um, dass es erneut nicht gelingen könne, in Deutschland ein freiheitliches und friedfertig gesinntes Staatswesen, das von der Zustimmung der Mehrheit seiner Bürger getragen würde, zu errichten. Er befürchtete, dass die Deutschen - nach der militärischen Niederlage und ihrer weltweiten moralischen Verdammung für die unter der nationalsozialistischen Despotie begangenen Untaten - ihr nationales Selbstverständnis erneut auf einer rückwärtsgewandten mythologischen Verherrlichung der Vergangenheit gründen könnten und sich dabei vor allem an der Epoche der deutschen Geschichte, die sich in ihrer Erinnerung durch äußeren Glanz und Größe auszeichnete, des Kaiserreiches von 1871-1914, orientieren würden (IV, 56). Dieses aber sah er von einer politischen Kultur des Untertanengeistes geprägt, die der Gesinnung, die er sich für die neue Republik erhoffte, diametral entgegengesetzt war. Zur Verdeutlichung seiner Auffassung zitiert er dazu eine Stelle aus dem Testament eines „,gescheiterten, abgründig Enttäuschten“, des Historikers und Nobelpreisträgers Theodor Mommsen (1817-1903): „Politische Stellung und politischen Einfluss habe ich nie gehabt und nie erstrebt; aber in meinem innersten Wesen, und ich meine, mit dem Besten, was in mir ist, bin ich stets ein animal politicum gewesen und wünschte ein Bürger zu sein. Das ist nicht möglich in unserer Nation, bei der der Einzelne, auch der Beste, über den Dienst im Gliede und den politischen Fetischismus nicht hinauskommt. [...] Ich habe in meinem Leben trotz meiner äußeren Erfolge nicht das Rechte erreicht. ${ }^{24}$

Aber auch im Rekurs auf die Weimarer Republik sah Sternberger keinen Grund für die Vaterlandsliebe. Sie sei gescheitert, weil kein Staat, der im Hass gezeugt sei, bestehen könne $(\mathrm{X}, 81)$. Es sei gerade „,das Vaterländische“ gewesen, das die Weimarer Republik gespalten habe. Diese Vokabel sei von den militant-restaurativen Parteien und der Rechten monopolisiert und als Kennwort missbraucht worden (X, 18). Sie hätten den „Patriotismus“ für sich in Anspruch genommen und diejenigen, die danach strebten, das Vaterland zu gewinnen, ihr Bürgerrecht zu stärken und ihre Abhängigkeit zu beenden, mit dem Schimpfwort der ,vater-

24 IV, 56. Der Text des Testaments wurde von Th. Mommsens Enkel Konrad Mommsen 1948 der „Wandlung“ zur Veröffentlichung übergeben und dort in Heft 1/1948 veröffentlicht. 
landslosen Gesellen“ verhöhnt. Es seien die „vaterländischen Verbände“ gewesen, die den „Staat von Weimar“ bekämpft hätten. Die Landsknechte, Verschwörer und Fememörder hätten „vaterländisch“ geheißen und den Patriotismus usurpiert (VI, 24 f.). Das „Vaterländische" habe die Ablehnung der parlamentarischen Demokratie, die als Oktroi der westlichen Verfassungsformen gesehen wurde, mit eingeschlossen. Die Weimarer Republik sei eine Republik ohne Republikaner, eine Demokratie ohne Demokraten gewesen (VII, 247).

1979, als er den Begriff des Verfassungspatriotismus prägte, sah Sternberger ernste Probleme für die Identitätsstiftung der Bundesrepublik. Ihre Bürger hätten eine gebrochene Loyalität zu einem geteilten Land. Indem die Bundesrepublik die Zugehörigkeit zu ihr nicht auf ihre Staatsbürger beschränke, sondern auf viele Millionen außerhalb des Bundesgebiets lebender tatsächlicher oder potenzieller deutscher Staatsangehöriger ausdehne und sich als Heimat aller Deutschen verstände, verzichte sie - als Statthalterin eines virtuellen Staates auf ein wesentliches Element spezifischen staatsbürgerlichen Bewusstseins (X, 88). Daraus ergebe sich eine labile Loyalität, die durch die Liebe zum Vaterland verfestigt werden müsse. Eine Gefährdung sah er auch darin, dass nach 1968 sich in Deutschland, wie auch in anderen westlichen Staaten, eine ,antipolitische, eigentlich anarchische Klasse“ gebildet habe, welche die Stabilität des Verfassungsstaates zu gefährden drohte. Ideologische Terroristen erschütterten das Land. Allen Versuchen, die Politik zu ,ideologisieren“ wohne ein Bestreben inne, durch eine religionsartige Bewegung oder mit der Forderung nach radikaler Demokratie, den wesenhaften Pluralismus im Verfassungsstaat zu beseitigen (VII, 11).

Aus diesen Erfahrungen und Erwägungen rief Sternberger entschieden zur Bewahrung der freiheitlichen parlamentarischen Verfassungsordnung auf. Das Grundgesetz habe sich, so urteilte er 1979, 30 Jahre nach seiner Verabschiedung, bewährt. Die auf ihm gründende lebendige Verfassung sei das Ergebnis eines erfolgreichen demokratischen Lernprozesses der Deutschen nach 1945. Deshalb könne das Grundgesetz das Symbol eines freien deutschen Vaterlandes sein und die Grundlage für einen deutschen demokratischen Patriotismus bilden. Mit dieser Begründung entsprach er dem Verfassungsverständnis des Parlamentarischen Rates. Nach dessen Willen sollte das Grundgesetz nicht nur ein verfassungsrechtlicher Text, sondern ein Dokument des neuen demokratischen Staatsverständnisses sein.

In den ersten Jahrzehnten der Bundesrepublik stimmten die großen politischen Parteien überein, dass das Grundgesetz den moralischen und verfassungsmäßigen Neuanfang Deutschlands symbolisiere. Die ausdrückliche Übernahme der Menschenrechte als Norm in das Grundgesetz der Bundesrepublik Deutschland wurde als der geschichtsträchtige Schritt verstanden, mit dem sich die Bundesrepublik ideell der freien Welt zuwende (Möbus 1965: 18). Das Grundgesetz wurde als Vermächtnis des deutschen Widerstandes gegen Hitler gesehen, denn eine der Quellen, die zu dem zentralen ersten Artikel des Grundgesetzes führten, beruhten auf den Gedanken des „Kreisauer Kreises“. ${ }^{25}$ Der ge-

25 Ein Entwurf Helmuth von Moltkes aus dem Jahre 1943 nannte als maßgebliche Ziele einer Neuordnung nach dem Sturz Hitlers vor allem die „Brechung des totalitären Gewissenszwangs“ und „die Anerkennung der unverletzlichen Würde der menschlichen Person als Grundlage der zu erstrebenden Rechts- und Friedensordnung“. Diese Vorstellungen des Kreisauer Kreises deckten sich mit den politischen Zielen des Vorstands der Sozialdemokratischen Partei Deutschlands im Londoner Exil. 
wollte Symbolcharakter des Grundgesetzes wurde durch die Geschichte seiner Verabschiedung dokumentiert. Für Konrad Adenauer war das Grundgesetz der erste Schritt zur moralischen und politischen Wiederbegründung Deutschlands. ${ }^{26}$ Das Grundgesetz ist vor allem als Konsequenz aus dem, den Mitgliedern des Parlamentarischen Rates bewussten Untergang der Weimarer Republik und dem miterlebten Unrechtsregime des Nationalsozialismus zu verstehen. In diesem Sinne war das Grundgesetz von Anfang an nicht nur, wie es in der damaligen Fassung der Präambel stand, eine Ordnung für eine Übergangszeit, sondern es griff weit hinaus über die damals nur für eine kurze Zeit erwartete Teilung. In diese Tradition stellte Sternberger seine Konzeption des Verfassungspatriotismus, er maß dem Grundgesetz eine ähnliche Symbolkraft für das Verhältnis der Bürger zur Bundesrepublik zu, wie sie die amerikanische Verfassung für die patriotische Gesinnung in den Vereinigten Staaten hat.

Der Begriff Verfassungspatriotismus füllte ein Vakuum, indem er die ,deutsche Identität" angesichts der Teilung auf die geschriebene Verfassung bezog und sie nicht mehr auf das ,Volk als ethnische, relativ homogene vorpolitische Schicksalsgemeinschaft“ gründete. Damit definierte Sternberger die Bundesrepublik als ein „modernes politisches Gemeinwesen", das zusammengehalten wird durch das politischen Wollen der Bürger. Staatliche Einheit ruht auf dem rationalen Willen des Einzelnen dazuzugehören und mitzumachen; sie ist Assoziation, nicht Korporation, nichts substanziell Vorgegebenes, sondern dynamisch Aufgegebenes (Buchstab/Uertz 2006: 19). Selbst ein entschiedener Kritiker des Verfassungspatriotismus, Otto Depenheuer, urteilt (2006: 66): „Der Fortschritt im Sinne der Rationalität liegt auf der Hand: Statt Tradition, Sprache oder ethnischer Volksangehörigkeit legitimiert und stiftet die aktive Wahrnehmung politischer Mitwirkungsrechte kollektive Identität, das heißt staatliche Einheit. Im Verfassungspatriotismus

26 Dies ist durch den Verlauf seiner Verabschiedung, insbesondere die Schlussberatung, belegt. Die 10. Plenarsitzung des Parlamentarischen Rates hatte am 8. Mai 1949 gegen 15 Uhr begonnen. Sie zog sich hin, weil sehr viele Wortmeldungen vorlagen. Eine halbe Stunde vor Mitternacht - zu diesem Zeitpunkt gab es noch sieben Wortmeldungen und es musste noch die zeitaufwendige namentliche Abstimmung stattfinden - stellte sein Präsident Konrad Adenauer fest: „Ich glaube, die meisten unter uns haben den Wunsch, dass unser Beschluss und damit das Grundgesetz das Datum des 8. Mai tragen möge. Es ist jetzt 11 Uhr 35 Minuten [...]. Die Franzosen lassen die Uhr stillstehen. Wir haben keine hier. Aber ich möchte die dringende Bitte an Sie richten, sich, wenn irgend möglich, so kurz zu fassen, dass wir vor 12 Uhr fertig werden“. Da sich bald ergab, dass in der verbleibenden kurzen Zeit nicht alle Wortmeldungen erledigt werden konnten, schlug Adenauer vor, zunächst die Schlussabstimmung stattfinden zu lassen und die restlichen Erklärungen hinterher anzuhören. So geschah es und das Grundgesetz wurde am 8. Mai 1949 auf den Tag vier Jahre nach dem Zusammenbruch des Hitlerregimes, gegen Mitternacht mit 53 Ja-Stimmen gegen 12 Nein-Stimmen beschlossen. Das Datum, an dem nach dem Willen des Parlamentarischen Rates das Grundgesetz verabschiedet wurde, sollte ein Symbol sein für den Geist, in dem die Entscheidung über die Grundlagen des neuen Staatwesens fiel (so mitgeteilt und bewertet von Ernst Benda in seiner Rede vor dem Deutschen Bundestag zum 50. Jahrestag der Verabschiedung des Grundgesetzes. Abgedruckt in: FAZ, 22.05.99). 
feiert der Universalismus der Vernunft einen Triumph: Es gibt nur noch Menschen, die den Staat rational zu ihrer Angelegenheit machen"“. ${ }^{27}$

Weil die Staatsverfassung der entscheidende Faktor zur Bewahrung der bürgerlichen Freiheit ist, lehnte Sternberger die Substituierung eines deutschen durch einen europäischen Patriotismus ab. Darin sah er eine Flucht vor der konkreten Herausforderung der den Bürgern aufgegebenen Gestaltung der Staatsnation. Verfassungspatriotismus dürfe nicht durch die Idee Europas ersetzt werden: „Ich zweifle, ob wir ein Recht haben, eine geschichtliche Wesenheit, wie sie doch gemeint ist mit diesem geographischen Namen ,Europa', zum Schatzhaus aller Ideale zu erklären, die uns teuer sind, und alle finsteren ,Komponenten' davon abzuziehen und fernzuhalten als bloßen Abfall und Verrat. Nein, es gibt keine Idee, die Europa hieße. Zum wenigsten scheint es besser, klarer, deutlicher und ehrlicher, die Ideen, denen wir folgen und zu denen wir uns bekennen wollen, bei ihren eigenen Namen zu nennen, und ebenso auch diejenigen, die wir verwerfen“ (X, 54). Auch in Europa bleibe, wie Sternberger 1980, zum Zeitpunkt eines damals politisch noch wenig integrierten Europa meinte, der nationale Verfassungsstaat der Bezugspunkt für die Gestaltung der Freiheit. ${ }^{28}$ In seinem Verständnis konnte der Europäischen Union nur dann eine eigene Legitimität zuwachsen, wenn sie sich zur föderativen, quasistaatlichen handlungsfähigen supranationalen Gemeinschaft weiterentwickle. Erst dadurch würde ein schrittweises Entstehen einer eigenen bürgerschaftlichen Identität ermöglicht. ${ }^{29}$

27 Depenheuer fährt dann allerdings fort, dass das Konzept des Verfassungspatriotismus in der Theorie richtig sein möge, aber nicht für die Praxis tauge, weil es zwar das irrationale Moment gewachsener nationaler Identität disziplinieren, aber nicht ersetzen könne. Darum geht es aber Sternberger mit seinem Begriff des Verfassungspatriotismus nicht. Er verkennt nicht, dass das Vaterland durch die vorhergehenden Generation gemacht wurde und damit schicksalsbedingt gegeben ist, aber er unterscheidet zwischen nationaler Zugehörigkeit und Patriotismus: Die Liebe und Loyalität zum Vaterland kann nur entstehen, wenn es sich in einer freien Verfassung erfüllt, nicht nur erlitten wird. Die beiden Beispiele, die Depenheuer anführt, sind deshalb nicht überzeugend: Die Bürger der DDR folgten, als sie sich für den Anschluss an die Bundesrepublik entschieden, nicht dem dumpfen, irrationalen Drang nach der nationalen Einheit, sondern ihrem Wunsch nach einem Leben in einer freiheitlichen und leistungsfähigen Demokratie. Auch die Bereitschaft zu einem Vereinten Europa entspringt weder dem Verdruss über den Nationalstaat noch dem irrationalen Drang nach einer neuen, europäischen Identität, sondern der rationalen Einsicht, dass ein deutscher Nationalstaat allein auf Dauer Freiheit, Sicherheit, Wohlstand und die Bewahrung der grundlegenden europäischen kulturellen Werte nicht gewährleisten kann.

28 Bei der Interpretation dieser Textstelle, die vor den Verträgen von Maastricht und Amsterdam und vor dem Entwurf einer europäischen Verfassung geschrieben wurde, muss, wie ausgeführt, gesehen werden, dass für Sternberger sich Patriotismus nur auf den Staat, die Republik als Gemeinschaft der Bürger beziehen kann, nicht auf eine nur ideelle Wertegemeinschaft.

29 Sternbergers Vorstellung wird von der Geschichte des Patriotismus in Deutschland gestützt. In einer durch eine Koalition der Monarchen mit der Elite des Adels, der Militärs und des aufstrebenden Bürgertums gebildeten Konföderation wurde das partikulare (preußische, bayrische, württembergische usw.) Staatsbewusstsein allmählich durch die infolge der wachsende Bedeutung der nationalen Institutionen (Reichstag und Reichsregierung), der nationalstaatlichen Gesetzgebung (z. B. BGB, Sozialgesetzgebung) und der nationalen Streitkräfte bewirkte, übergreifende nationale Identität überwölbt. Allerdings vollzog sich dieser Prozess nur schrittweise und er zeigt auch die Grenzen einer von oben verfügten Identitätsgewinnung, denn ein von Klassen- und Nationalitätenkampf, von Hass, Ausgrenzung oder dumpfer Irrationalität freies Staatsbewusstsein erfüllte sich letztlich erst durch die bürgerschaftliche Verfassung des Grundgesetzes von 1949 und die Ausdehnung seiner Gültigkeit auf das ganze Deutschland 1990. 
Sternberger hielt sich bei der Begründung des Verfassungspatriotismus nicht damit auf nachzuweisen, inwieweit einzelne Bestimmungen des Grundgesetzes sich bewährt hatten, obwohl er dafür seinerzeit mit den von ihm initiierten Forschungsprojekten zum Parlamentarismus, die sich eingehend empirisch mit dem Funktionieren der Verfassung im engeren und im weiteren Sinne, als lebendige Verfassung befassten, einen wichtigen Forschungsbeitrag geleistet hat. Das Grundgesetz hielt er für eindeutiger und funktionsfähiger als je zuvor eine deutsche Verfassung: Es ermögliche eine stabile handlungsfähige Regierung, eine kräftige, an der politischen Gestaltung mitwirkende Opposition und den Wechsel von Regierung und Opposition. Es habe eine Gerichtsbarkeit geschaffen, die Verwaltung und Gesetzgebung wirksam kontrollieren könne und die politische Machtübung in Grenzen halte. Es ermögliche die Mitwirkung der gesellschaftlichen Organisationen und eine vielfältige öffentliche Meinung (X, 13-16). Sternberger sah die Qualität des Grundgesetzes, trotz aller Mängel im Detail, immer im Vergleich zur unglücklichen und zweideutigen Weimarer Verfassung, die eine parlamentarische Demokratie ohne wahrhaft und entschiedene parlamentarische Regierung gewesen sei, die die notwendige Führungsfunktionen vernachlässigt und keine ausreichende Autorität gehabt habe. Die Regierungen der Weimarer Republik hätte von Beginn an eine Autoritätscheu gezeigt, welche die totalitäre Perversion herausgefordert habe (VII, 247 f.).

Zehn Jahre nach Sternbergers Tod und nach der Wiedervereinigung urteilte Jürgen Gebhardt, dass die subjektive Integration Deutschlands in einer anfangs von ihren geschichtlichen Voraussetzungen her regional, sozial und ideologisch vielfach fragmentarisierten politischen Kultur das Resultat eines verfassungstheoretisch und institutionspolitisch von der politischen Elite vorgegebenen objektiven Selbstverständnisses der Republik gewesen sei. Dieses habe der Republik ihre legitimierende Leitidee in Gestalt der Verfassung vermittelt. Der Verfassung sei von Anbeginn an die zentrale Ordnungsfunktion der Integration zugewachsen. Die langfristige Wirkung dieser Ordnungsfunktion beruhe darauf, dass die Ordnungsgehalte der Verfassung zum verbindlichen Bezugspunkt der politischen Deutungskultur in Deutschland wurden. Die Herausbildung einer für die deutschen Verhältnisse spezifischen Mischung etatistischer und bürgerschaftlicher Elemente in einer in sich durchaus stimmigen, utilitaristisch ausgerichteten, demokratischen politischen Kultur gehe ursächlich auf das kraftvolle und dauerhafte Zusammenspiel der symbolischen und instrumentellen Ordnungsfunktion der Verfassung zurück. Der individuell-subjektive Aspekt der Grundloyalität zum Gemeinwesen sei durchaus ein Argument für die verfassungspatriotische Deutung der politischen Kultur (Gebhardt 1999: 25 f.).

Sternberger sah den Grund für den Erfolg des Grundgesetzes in seinem Charakter als „gemischte“ Verfassung, bei der das demokratische Element die Wählerschaft darstelle, das oligarchische die ,politische Klasse“, die aus der Staatsgesellschaft hervorwachse, „ohne feste sozialökonomische Konturen dank jener eigentümlichen bürgerlichen Organisationen, die wir politische Parteien nennen“ (X, 152). Zwar sah auch er die Mängel der Verfassung. Ein Hauptmangel schien ihm das Wahlrecht, das die Art der Verbindung von demokratischen und oligarchischen Elementen, die für die gemischte Verfassung konstitutiv sei, bestimme. Viele Jahre kämpfte er deshalb mit der von ihm mitbegründeten und geführten „Deutschen Wählergesellschaft“ für das relative Mehrheitswahlrecht, von dem er 
sich eine bessere Mischung der Elemente versprach. Das deutsche System der Proporzwahl verstärke durch die damit den Parteien gegebene Macht das oligarchische Element (VII, 343). Nach einem jahrzehntelangen vergeblichen Kampf für eine Wahlrechtsreform resignierte er schließlich: Es sei zu spät für die Einführung des relativen Mehrheitswahlrechts, weil sich die Bürger wegen seiner langen Geltungsdauer an das bestehende Wahlrecht trotz seiner Mängel gewöhnt hätten und es loyal für gerecht hielten (VII, 349).

Auch die Überbetonung des Rechtsstaats schien ihm problematisch, denn der spezifisch deutsche Gedanke des Rechtsstaates habe recht wenig mit dem Verständnis des Staates aus bürgerlicher Verantwortung zu tun, er stamme aus der Epoche des aufgeklärten Absolutismus und seiner Verwaltungsreformen und rechtfertige die Herrschaft der Bürokratie, verleihe aber der Legalität der bürokratischen Verwaltung keine Rechtmäßigkeit und Legitimität. Nicht ein bürokratischer Rechtstaat, sondern der Verfassungsstaat führe zu einer guten Politik (III, 138).

Trotz der Mängel des Grundgesetzes kam er zum Schluss, dass es sich im Großen bewährt habe: „Wir brauchen uns nicht zu scheuen, das Grundgesetz zu rühmen“ (X, 15). Diesem Urteil stimmen viele Kenner der bundesrepublikanischen Entwicklung zu, auch vehemente Kritiker des Verfassungspatriotismus (Scholz 2004: 67). Die Verfassung in ihrer glücklichen Mischung von Parlamentarismus, starker Stellung des Bundeskanzlers, Föderalismus und Verfassungsgericht habe den Rahmen dafür geschaffen, dass Deutschland zu einem vorbildlichen Rechts- und Sozialstaat und zum Motor der europäischen Einigung geworden sei.

\section{Kritik am Verfassungspatriotismus und die Wiederkehr des Nationalpatriotismus}

Trotz des unbestrittenen Erfolgs des Grundgesetzes mehren sich die Stimmen, die es als Bezugspunkt des Patriotismus für nicht geeignet halten. Nach der großen Resonanz in den 80er-Jahren stieß das Legitimationsmuster des Verfassungspatriotismus zunehmend, vor allem bei den Verfechtern eines neuen Nationalpatriotismus auf Kritik. Die Frage nach der Identität, der Staatsidee und der Berufung Deutschlands ist auch zu Beginn des 21. Jahrhunderts nicht verstummt. ${ }^{30}$ Der eigentliche Grund für Sternbergers Reflexion über den Patriotismus war das beunruhigende Faktum der unsicheren deutschen Identität: „Wir wissen nicht, wer wir sind. Das ist die deutsche Frage. Es gibt nahezu nichts, kein Ziel, keine Form des gemeinsamen Lebens, die hier mit ganzem Herzen ergriffen und ausgebildet werden könnte. Auf jeder möglichen Gestalt deutschen Daseins liegt ein Schatten“ (Sternberger 1949: 16). Arnulf Baring (1988: 33) hat kurz vor der Wiedervereinigung - an diesen Satz anknüpfend - auf die geschichtlichen Unausgeglichenheiten und die Unsicherheit der Deutschen, ihre Möglichkeiten und ihre Grenzen zu erkennen, hingewiesen.

30 Davon zeugt, zumindest im konservativen Spektrum, die wieder aufgeflammte und eingangs erwähnte Diskussion um eine deutsche Leitkultur und den Wunsch nach einem neuen „Patriotismus“. Dazu neuerdings die von der Konrad-Adenauer-Stiftung herausgegebene Zeitschrift „Die politische Meinung“, Nr. 435, Februar 2006. 
Die neu aufgeflammte Diskussion um den Verfassungspatriotismus und Nationalpatriotismus ist deshalb besonders geeignet, den Kern der Sternberger'schen Argumentation zu verdeutlichen.

Die Kritik bezieht ihre Rechtfertigung aus der Wiedervereinigung 1990, mit der Deutschland seine Einheit und seine volle Souveränität erlangte und damit wieder ein „,normaler" Nationalstaat wurde. Es sei an der Zeit, dass die Deutschen, wie ihre Nachbarn, sich endlich auch als eine normale Nation verstünden. Patriotismus sei die unverzichtbare Grundlage des die Gesellschaft zusammenhaltenden Staatsbewusstseins, nur damit könne es gelingen, die Deutschen zu neuer Solidarität und zu einem neuen Aufbruch zu motivieren, Verfassungspatriotismus dagegen sei ein postnationaler Begriff, der die Tatsache negiere, dass der Nationalstaat weiterhin das politische Ordnungsprinzip Europas sei (Scholz 2004: 14).

Ein Patriotismus, der sich nur auf ein „abstraktes, dehnbares Rechtsdokument“ wie das Grundgesetz beziehe, genüge nicht für die inhaltliche Bestimmung des nationalen Gemeinwohls (Kronenberg 2004: 31). Paragrafen, Verfassungsartikel und das Grundgesetz, das nur eine vorläufige Verfassung gewesen sei, könne man nicht lieben. Der Begriff sei sozial, räumlich und geschichtlich indifferent (Behrmann 1993: 8). Verfassungspatriotismus sei „geschichtsvergessen“, er verdränge die positiven Seiten der deutschen Geschichte. Es habe in Deutschland nicht nur nationalen Größenwahn, Kriegsschuld und Verbrechen gegeben, sondern große Kulturleistungen und respektable und erfolgreiche politische Leistungen, die nicht ,eingeebnet“ werden dürften. ${ }^{31}$ Es gehe um ein neues, sinnvolles Nationalbewusstsein, es gelte wieder, den Stolz auf das eigene Land zu wecken und die Einheit der Nation auf ein gesundes Geschichtsbewusstsein zu gründen.

Der Verfassungspatriotismus negiere die geschichtlich gewachsene Schicksals- und Erlebnisgemeinschaft. Nationalbewusstsein entstehe erst aus dem Akt nationaler Selbstbestimmung, der aus ethnischen und kulturellen Gemeinschaftsstrukturen erwachse (Scholz 2004: 16). Angesichts zunehmender Individualisierung, der Entstehung von Parallelgesellschaften durch Immigration, abnehmender Fähigkeit des Sozialstaats und wachsender Internationalisierung stelle sich die Frage, was die Gesellschaft zusammenhalte und was Gemeinwohlbezogenheit der Bürger stifte (Buchstab/Gauger 2004). Nationalbewusstsein gründe zu nicht unerheblichen Teilen in den der rationalen Reflexion nur schwer zugänglichen Tiefenschichten des kollektiven Unbewussten. „Gerade aber in der Anerkennung dieses irrationalen Elements staatlicher Einheit liegt zugleich die notwendige Befriedigung

31 Diese Position greift die im 19. Jahrhundert entstandene und seither weit verbreitete Auffassung wieder auf, dass sich das deutsche Volk durch besondere Kulturleistungen auszeichne. Die deutsche Kultur sei einer der unverzichtbaren „Bausteine der großen Menschheitskultur“. Sie sei das Ergebnis einer langen Geschichte „,von tausend Jahren“, in der das deutsche Volk erst spät nach dem Krieg gegen Frankreich 1870/71 zur Einigung gefunden habe. Die Geschichte sei das innere Band, das die Generationen verbinde und die Nation zusammenhalte und zu emotionalen, Hingabe, Engagement und Opferbereitschaft führe. So http://www.cdu-sachsen.de/de/partei/ Landesparteitage/19_LPT/ Patriotismuspapier [Beschluss 2005_fürs web(1).pdf : Beschluss des 19. Landesparteitags der CDU Sachsen am 19.11.05, Zugriff am 25.02.06] sowie Rößler 2006. 
elementarer emotionaler Bedürfnisse der Menschen [,...denn] das Volk lebt weder von Brot noch von Begriffen allein; es will durchaus etwas Positives zu lieben, zu sorgen und sich daran zu erfrischen, es will vor allem eine Heimat haben in vollem Sinne, d. h. seine eigentümliche Sphäre von einfachen Grundgedanken, Neigungen und Abneigungen, die alle seine Verhältnisse lebendig durchdringen und in keinem Kompendium registriert stehen“ (Depenheuer 2006: 68). Auch die Deutschen hätten das Recht, sich als eine auf ethnische und kulturelle Gemeinschaftsstrukturen gründende, geschichtlich gewachsene Schicksals- und Erlebnisgemeinschaft zu verstehen. Deshalb sei „Verfassungspatriotismus“ als nationales Identitätselement und Identifikationsgrundlage ein irreführendes „Schein-Konzept“ (Scholz 2004: 17). Die breite Debatte über den neuen Patriotismus ist nicht nur ein kurzfristige Modethema ${ }^{32}$, sondern weist auf die nach wie vor strittigen Identitätsprobleme in der politischen und intellektuellen Elite Deutschlands hin. ${ }^{33}$ Von nationalpatriotischer Seite wird der Verfassungspatriotismus in erster Linie als Projekt einer postnationalen und multikulturellen Linken angesehen. Die Kritik an ihm bezieht sich deshalb vornehmlich auf seine Interpretation durch Habermas.

Es ist nicht zu verkennen, dass durch diese Diskussion der eigentliche Kerngedanke Sternbergers bereits kurz nach seiner Prägung verdunkelt zu werden drohte. Er selbst klagte, er sei missverstanden worden. Er habe keinen Ersatz für den nationalen Patriotismus bieten wollen, ,vielmehr wollte ich darauf aufmerksam machen, dass Patriotismus in einer europäischen Haupttradition schon immer und wesentlich etwas mit Staatsverfassung zu tun hatte, ja dass Patriotismus ursprünglich und wesentlich Verfassungspatriotismus gewesen ist - und freilich auch, dass er es heute in Deutschland noch und wieder sein könnte“ (X, 32).

Gegenüber dem normativen Postulat einer republikanischen patriotischen Gesinnung durch Sternberger, begründet Habermas den Verfassungspatriotismus mit der historischen Entwicklung. In Europa habe im 19. Jahrhundert eine nationalstaatliche Fusion der Elemente des Republikanismus und des Nationalismus stattgefunden, wobei Letzterer eine artifizielle Bewusstseinsformation sei, die mit der akademischen Hilfe von Historikern, Volkskundlern, Juristen, Sprach- und Literaturwissenschaftlern konstruiert, über Schule und Familie in die Erziehungsprozesse eingeschleust, über die Massenkommunikationsmittel verbreitet und durch die allgemeine Wehrpflicht verankert worden sei. Diese Fusion habe sich nach zwei Weltkriegen gelockert und verliere weiter an Bindungskraft durch die abnehmende Bedeutung des Nationalstaates. Daraus ergebe sich die Möglichkeit, die

32 Kardinal Karl Lehmann, der Vorsitzende der Deutschen Bischofskonferenz, in: Frankfurter Allgemeine Sonntagszeitung, 12.12.04, S. 2. Er halte die gegenwärtige Diskussion über Patriotismus für oberflächlich. Eine romantische Verklärung von Vaterland und Heimat führe nicht weiter. Das Thema flamme seit 30 Jahren immer wieder kurz auf und ende schnell wieder, es sei eine modische Welle.

33 Aufschlussreich ist die lebhafte Diskussion, die sich in Berichten, aber vor allem in Leserbriefen in der Presse niederschlägt. Sie zeigt, dass in Teilen der öffentlichen Meinung das Thema engagiert diskutiert wird. Eine Internetsuche (01.02.06) ergab allein in der FAZ für den Begriff ,Verfassungspatriotismus“ 178 Treffer, für „Patriotismus“ und „Nationalbewusstsein“ der Deutschen ist die Zahl um ein Vielfaches höher. 
staatsbürgerliche Solidarität über die jeweiligen nationalen Grenzen hinaus zu einer wechselseitigen europäischen Inklusion zu erweitern. Republikanische Gesinnungen lösten sich allerdings von ihren vorpolitischen Verankerungen nur in dem Maße, wie die demokratischen Praktiken auf europäischer Ebene eine eigene Dynamik öffentlicher Selbstverständigung entfalteten (Habermas 2004: 76 ff.). Im Hintergrund dieser Argumentation steht allerdings seine tiefe Skepsis gegen das ambivalente Potenzial des deutschen Nationalismus. Habermas vertraut nicht auf die Überwindung des irrationalistischen antidemokratischen Unterstroms der deutschen politischen Überlieferung (Habermas 1995: 16), sondern setzt seine Hoffnung auf eine institutionell demokratisch ausgebaute Europäische Union, welche Verantwortung für eine kooperative Lösung der globalen Probleme übernehmen könne (Habermas 1995: 187 f.). Dagegen hoffte Sternberger schon 1947, dass in Deutschland die Verfassungspatrioten die Mehrheit gewinnen könnten, um die Freiheit zu sichern (IV, 31-32) und sah sich darin 1979 bestätigt.

Der grundsätzliche Unterschied zwischen Habermas und Sternberger ist allerdings wohl doch nicht so signifikant, wie die Kritiker des Verfassungspatriotismus meinen (Kronenberg 2005: 189-215). Beide sind überzeugte Republikaner. Gemeinsamkeiten gibt es auch in der Ablehnung von Carl Schmitts Vorstellungen vom starken Staat, der geborenen nationalen Einheit und der Homogenität der Nation (Habermas 1988: 112), aber auch hinsichtlich der Beurteilung der Bedeutung des nationalsozialistischen Regimes und des Holocausts für das deutsche Selbstverständnis. Für beide bedeuten diese einen tiefgehenden Zivilisationsbruch, der für die deutsche Identität grundlegende Bedeutung hat. ${ }^{34}$ Sie stimmten auch darin überein, dass keine auf die deutsche Geschichte Bezug nehmende Begründung des deutschen Patriotismus an der Tatsache des nationalsozialistischen Unrechtssystems und vor allem des von ihm begangenen Genozids an den Juden vorübergehen kann. Deshalb kann ein Deutscher, so Sternberger, nicht in gleichem Maße stolz auf die Geschichte seiner Nation sein, wie ein Franzose, Engländer oder Amerikaner. ${ }^{35}$ Die Verfechter des neuen Nationalpatriotismus neigen in diesen Fragen eher zu einer relativierenden Position. ${ }^{36}$

34 Diese Fragen standen auch im Zentrum des Historikerstreits, zu dem Sternberger nicht mehr öffentlich Stellung nahm. Dabei ging es u. a. darum, ob die nationalsozialistische Vernichtungspolitik und der Holocaust nur einen Einschnitt darstellten oder als eine tiefe Zäsur im deutschen Selbstverständnis verstanden werden müssten, ob wirklich Deutschland unter Hitler die alleinige Schuld am Zweiten Weltkrieg trüge und ob die Vertreibung der Deutschen aus Osteuropa die schwerwiegendste Kriegsfolge gewesen sei (Wehler 1988: 8).

35 Dagegen Rößler (2006: 8): „Über achtzig Prozent der Deutschen meinen, als Deutscher könne man genauso stolz sein auf sein Land wie als Franzose, Amerikaner oder Engländer“. Die deutsche Schuld am Holocaust und der nationalsozialistischen Besiedlungspolitik in Osteuropa wird vor allem auch bei den Befürwortern eines „Zentrums gegen Vertreibungen“ relativiert, der deutsche „Kulpismus“ sei angesichts der Vertreibung und des alliierten Bombenkriegs nicht gerechtfertigt und als ,negativer Nationalismus“ abzulehnen.

36 Im Historikerstreit wurde diese von konservativen Historikern, wie Ernst Nolte, Hillgruber, Hildebrand und Stürmer, vertreten. 
Wegen dieser nicht unerheblichen Einschränkung bezüglich des Verständnisses der deutschen Geschichte ist allerdings doch die Frage berechtigt, ob sich die deutsche Identität in Zukunft nur auf das nach innen gerichtete Staatsverständnis des Verfassungspatriotismus gründen kann. Sie drängt sich um so mehr angesichts des ungebrochenen Staatsnationalismus der anderen westeuropäischen Staaten und des betont ethnischen Nationalgefühls der neu zur Europäischen Union hinzugetretenen osteuropäischen Staaten auf (Krossa 2004). Kann es einen europäischen Verfassungspatriotismus im Sternberger'schen Sinne geben, solange die Europäische Union nur auf der Vereinbarung der Regierungen beruht und keine dem Parlament verantwortliche Regierung hat? Was bedeuten die Unwägbarkeiten der weiteren politischen Integration Europas für das deutsche Selbstverständnis ? ${ }^{37}$ Ist nicht das Konzept des europäischen Nationalstaats insgesamt überholt? Was bedeutet es für dieses Konzept, dass sein Export in die neuen Staaten Afrikas, Asiens und Lateinamerikas eher destabilisierende Wirkungen hatte (Reinhardt 2000: 480-536)? Die internationale Dimension des nationalen Selbstverständnisses kommt in der deutschen Diskussion zu kurz.

\section{Ausblick}

Die Wirkung des „Verfassungspatriotismus“ ist ein gutes Beispiel, wie eine im Gesamtwerk eines Publizisten und Wissenschaftlers eher beiläufige Begriffsprägung geschichtsund gesellschaftsrelevant wird. Sicher trug dazu bei, dass der „Erfinder“ Sternberger sich nimmermüde bemühte, seine Ideen zu kommunizieren. Durch seine über Jahrzehnte sich ersteckenden regelmäßigen Beiträge in der FAZ, seine Radiobeiträge im Hessischen Rundfunk, seine Zeitschriftenartikel, vielfältigen Vorträge und durch seine Mitarbeit in den verschiedensten Gremien legte er selbst dazu die Grundlage (Haungs 1977: 19).

Die breite Anerkennung der auf den Begriff gebrachten Doktrin setzte aber auch ein dafür aufnahmefähiges intellektuelles Klima bei den meinungsführenden Eliten voraus (Giesen 1999: 18). Nach dem turbulenten Jahrzehnt zwischen 1968 und 1978 war der Begriff Verfassungspatriotismus angesichts des problematischen Staatsverständnisses der Deutschen eine „geniale“ Begriffsprägung (Buchstab/Uertz 2006: 19). Er spiegelte eine bis dahin nur gefühlte oder kompliziert umschriebene politische und wissenschaftliche Realität. Während der Begriff der gleichzeitigen Delegitimierung des essentialistischen Verständnisses von Nation und dem langen und erfolgreichen Weg zur westlichen „Staatsnation" entsprach, ermöglichte er eine generationen- und parteienübergreifende Grundloyalität zur demokratischen Ordnung und versprach einen sich auf die bürgerschaftliche Vereinbarung gründenden modernen Staat.

Nach der Wiedervereinigung zeigte sich, dass der Begriff für viele Konservative nur ein Kompromiss und Notbehelf gewesen war. Sie hielten die Stunde gekommen, einen emotionalen, in der deutschen Geschichte verankerten nationalen Patriotismus wiederzu-

37 Eine Bestandsaufnahme des nationalen Identität in Europa findet sich bei Buchstab/Uertz 2006. 
beleben. Für sie ist die Sternberger'sche Konzeption des Verfassungspatriotismus eine ärgerliche Gegenposition, denn diese ist keineswegs „links“, sondern nationalstaatsbezogen und republikanisch, sie reflektiert die in der aristotelischen Philosophie verankerten politischen Normen und ist konsequent rational.

Natürlich ist der Begriff Verfassungspatriotismus sperrig und auslegungsbedürftig im Hinblick auf die lebende Verfassung, die er meint, auf die ihm zugrunde liegende Legitimitätsvorstellung und auf das Konzept der gemischten Verfassung. Aber auch der ihm gegenüber gestellte neue Nationalpatriotismus benötigt Zusätze, wie ,aufgeklärt“, „modern“, „freiheitlich“, „,demokratisch“, „offen“, „tolerant“", „gemeinwohlbezogen“, „werteorientiert“, „heimatbezogen“, „geschichtsbewusst“" usw., um sich von Missverständnissen abzugrenzen. Die Befürworter eines neuen „normalen“ Nationalpatriotismus bemühen sich deshalb auch die Gemeinsamkeiten mit der Sternberger'schen Position heraus zu stellen. Es sei nicht einzusehen, warum die verfassungspolitische Identität gegenüber der nationalen Identität der Deutschen ausgespielt werden solle (Kronenberg 2005: 201).

Das irrationale Element des neuen Nationalpatriotismus, die geforderte emotionale Bindung an ein nationales Kollektiv, ist mit Sternbergers Argumentation nicht vereinbar. Er vertrat kompromisslos die Ansicht, dass diejenigen Regierungen, die aus Wahlen hervorgehen und diejenigen Verfassungen, die auf bürgerlicher Vereinbarung gegründet sind, keinen irrationalen „Legitimitätsglauben“ verlangen. Ihre Rechtmäßigkeit ,gründet auf dem Selbstvertrauen des Menschen, auf der Einsicht in die gesellige, bürgerliche, politische Natur des Menschen, oder, wenn man will, auf dem freien Entschluss zum Staat und auf der Kraft zu einem solchen Entschluss“ (VII, 362). Sternberger geht von der Freiheit und Gleichheit des Individuums aus, er setzt auf die Vernunft des freien Bürgers, seinen Common Sense und seine Verantwortung gegenüber dem Staat. Die Jugend müsse in diesem Sinne erzogen und die Bürger ständig angehalten werden, einen angemessenen Beitrag zum allgemeinen Wohl, zu den Staatsangelegenheiten zu leisten. Daraus kann, wie Sternberger immer wieder betont, eine gefühlsmäßige Bindung, Staatsfreundschaft, ja Staatsleidenschaft erwachsen, jedoch steht diese Emotionalität nicht im Gegensatz zur Vernunft. Auch aus konservativer Sicht ist die Vernunft ein besserer Ratgeber und Wegweiser für grundlegende politische Entscheidungen als kollektiv erzeugte, nicht reflektierte nationale Gefühle (Oberndörfer 1995: 49).

Die Akzeptanz der Sternberger'schen Argumentation des Verfassungspatriotismus bedeutet, von der Inanspruchnahme kollektiver Emotionen und historischer Mythen für ein neues deutsches Nationalgefühl abzusehen und der tiefen Zäsur von 1945 den ihr zukommenden Platz im Verständnis deutscher Geschichte einzuräumen. Es ist die Besonderheit Deutschlands, dass im Unterschied etwa zu Frankreich und den USA die republikanische Gesinnung sich nicht in einem langen kontinuierlichen historischen Prozess entwickelte. Die Geschichte der deutschen Republik beginnt erst nach der tiefen Zäsur von 1945. Sechzig Jahre danach können die Deutschen stolz darauf sein, dass ihr Land den wirtschaftlichen Wiederaufbau geschafft hat, als demokratisches Staatswesen zur westlichen Wertegemeinschaft gehört, zu einem Pfeiler der europäischen Versöhnung und Einigung 
geworden ist und dass es zum ersten Mal seit 200 Jahren nicht mehr als die bedrohende und hässliche Nation im Herzen Europas, sondern in Ost und West als guter Nachbar angesehen wird. Es ist für Deutschland kein kultureller und außenpolitischer Nachteil, wenn sich die Vaterlandsliebe seiner Bürger „nur“ auf einen nach dem Neubeginn 1949 und der Wiedervereinigung 1990 besonders der Freiheit und der Humanität verpflichteten Staat bezieht. Ein solches Verständnis entspricht vielmehr eher dem Empfinden der jüngeren Generation und trägt dazu bei, die immer noch bestehenden Ängste unserer Nachbarn vor Deutschland zu mindern.

Der Verfassungspatriotismus bezieht sich auf die Werte, die das Handeln des Staates bestimmen. Diese können aber in der Republik nur in der Verfassung festgeschrieben werden, jenseits davon gibt es keine religiösen oder kulturellen Werte und Verhaltensweisen, die für die Bürger verbindlich gemacht werden dürfen (Oberndörfer 1995: 48). Patriotismus kann sich allerdings nicht nur auf die grundlegenden Normen der inneren staatlichen Ordnung beziehen, sondern er ist immer auch nach außen gerichtet. Weder aus der Auffassung der Nation als Schicksalsgemeinschaft noch aus dem Verfassungspatriotismus ergeben sich konkrete außenpolitische Ziele. Für die Festigung des nationalen Selbstverständnisses der Deutschen ist es deshalb erforderlich, über die zukünftige Rolle Deutschlands in Europa und in der Welt nachzudenken und darüber einen Konsens oder zumindest eine von einer substanziellen Mehrheit der Bürger getragene Entscheidung zu finden. Kann und soll Deutschland danach streben, eine europäische große Macht zu werden, die ihren eigenen Weg geht und selbstbewusst ihre nationalen Interessen vertritt? Oder liegt Deutschlands Berufung, seine Staatsidee, als „Zivilmacht“ in der Stärkung Europas und der transatlantischen Wertegemeinschaft? Wie soll die Europäische Union gestaltet werden, welche Kompetenz soll sie gegenüber ihren Mitgliedsstaaten haben, wo soll sie ihre Grenzen haben? Wie soll die Bundesregierung den aller Wahrscheinlichkeit nach andauernden Zustrom von Immigranten steuern und wie kann sie die Integration der Zuwanderer in die Verfassungsgemeinschaft deutscher Staatsbürger besser gestalten? Wie kann sichergestellt werden, dass die im Grundgesetz verankerten Werte von allen, die als Bürger oder als Zuwanderer in Deutschland leben, anerkannt und gelebt werden?

„Verfassungspatriotismus“ kann nicht sozialwissenschaftlich begründet werden, er ist ein ethisch begründetes politisches Postulat. Der Gehalt des Verfassungspatriotismus, wie er von Dolf Sternberger definiert wurde, ist trotz seiner sperrigen und interpretationsbedürftigen Bezeichnung geeignet, auch weiterhin Orientierung für den inneren Frieden und Zusammenhalt im geeinten Deutschland sowie für die Zukunft der Europäischen Union zu geben und als Richtschnur für das nationale Selbstverständnis der Deutschen zu dienen. 
Peter Molt

\section{Literatur}

Augstein, Rudolf u. a., 1987: Historikerstreit. Die Dokumentation der Kontroverse um die Einzigartigkeit der nationalsozialistischen Judenvernichtung, München (Sammlung Piper).

Baring, Arnulf, 1988: Unser neuer Größenwahn - Deutschland zwischen Ost und West, Stuttgart.

Behrmann, Günter, 1993: Verfassung, Volk und Vaterland. Zur historischen, pädagogischen und politisch-kulturellen Verortung des Verfassungspatriotismus, in: ders./Siegfried Schiele (Hrsg.), Verfassungspatriotismus als Ziel der politischen Bildung?, Schwalbach.

Behrmann, Günter C., 1999: Die Erziehung kritischer Kritiker als neues Staatsziel, in: Clemens Albrecht u. a., Die intellektuelle Gründung der Bundesrepublik. Eine Wirkungsgeschichte der Frankfurter Schule, Frankfurt a. M., 448-496.

Breuer, Stefan, 1997: Rationale Herrschaft. Zu einer Kategorie Max Webers, in: Seibel u. a. $1997,106-134$.

Buchstab, Günter/Gauger, Jörg-Dieter, 2004: Was die Gesellschaft zusammenhält. Plädoyer für einen modernen Patriotismus, Sankt Augustin (Konrad-Adenauer Stiftung Zukunftsforum Politik Nr. 62).

Buchstab, Günter/Uertz, Rudolf (Hrsg.), 2006: Nationale Identität im Vereinten Europa, Freiburg.

Depenheuer, Otto, 2006: Nationale Identität und europäische Gemeinschaft. Grundbedingungen politischer Gemeinschaftsbildung, in: Buchstab/Uertz 2006, 55-74.

Elias, Norbert, 1992: Studien über die Deutschen, Frankfurt a. M.

Friedrich, Carl J. (Hrsg.), 1968: Sprache und Politik. Festgabe für Dolf Sternberger zum 60. Geburtstag, Heidelberg.

Gebhardt, Jürgen, 1999: Verfassung und politische Kultur in Deutschland, in: ders. (Hrsg.), Verfassung und politische Kultur, Baden-Baden, 15-32.

Giesen, Bernhard, 1999: Kollektive Identität, Frankfurt a. M.

Habermas, Jürgen, 1995: Die Normalität einer Berliner Republik. Kleine Politische Schriften VIII, Frankfurt a. M.

Habermas, Jürgen, 2004: Der gespaltene Westen. Kleine Politische Schriften X, Frankfurt a. M.

Hacke, Christian, 2003: Die Außenpolitik der Bundesrepublik Deutschland. Von Konrad Adenauer bis Gerhard Schröder, Frankfurt a. M.

Hanke, Edith/Mommsen, Wolfgang J. (Hrsg.), 2001: Max Webers Herrschaftssoziologie. Studien zur Entstehung und Wirkung, Tübingen.

Haungs, Peter (Hrsg.), 1977: Res Publica. Studien zum Verfassungswesen, München.

Haungs, Peter, 1992: Staatsbewusstsein im vereinigten Deutschland. Verfassungspatriotismus oder was sonst?, in: Oscar W. Gabriel (Hrsg.), Der demokratische Verfassungsstaat. Theorie, Geschichte, Probleme. Festschrift für Hans Buchheim zum 70. Geburtstag, München. 
Helmerich, Antje, 2004: Ethnonationalismus und das politische Potenzial nationalistischer Bewegungen 2004, in: APuZ, B 39, 19-24

Hennis, Wilhelm, 1977: Vom gewaltenteilenden Rechtsstaat zum teleokratischen Programmstaat - Zur lebenden Verfassung der Bundesrepublik, in: Haungs 1977, 170195.

Kielmansegg, Graf Peter von, 1997: Legitimität als analytische Kategorie, in: Seibel u. a. 1997, 62-96.

Koch, Guido, 2005: Nation und Nationalismus bei Meinecke, in: ZPol 15, 419-445.

Kronenberg, Volker, 2004: Patriotismus in Deutschland. Eine Nation auf der Suche nach sich selbst, in: Die Politische Meinung, Nr. 421, Dezember.

Kronenberg, Volker, 2005: Patriotismus in Deutschland. Perspektiven für eine weltoffene Nation, Wiesbaden.

Krossa, Anne Sophie. 2004: Das Konzept „,Verfassungspatriotismus“ im Kontext der Erweiterung der Europäischen Union. Eine kritische Betrachtung am Beispiel Polens. DFG-Graduierten-Kolleg „Europäische Integration und gesellschaftlicher Strukturwandel“", http://data.sozialwiss.uni-Osnabrück.de/_dfgkolleg/texte/krossa_vs.html (Download vom 18.02.06).

Lietzmann, Hans J., 1993: „Verfassungspatriotismus“ und „,civil society“. Eine Grundlage für die Politik in Deutschland?, in: Rüdiger Voigt (Hrsg.), Abschied vom Staat - Rückkehr zum Staat?, Baden-Baden.

Lietzmann, Hans J., 1999: Integration und Verfassung oder: Gibt es eine Heidelberger Schule der Politikwissenschaft?, in: Wilhelm Bleek/Hans J. Lietzmann (Hrsg.), Schulen in der Politikwissenschaft, Opladen.

Meinecke, Friedrich, 1963: Weltbürgertum und Nationalstaat. Herausgegeben und eingeleitet von Hans Herzfeld, München (9. Aufl.).

Meinecke, Friedrich, 1968: Politische Schriften und Reden. Herausgegeben und eingeleitet von Georg Kotoswki, Darmstadt (3. Aufl.).

Möbus, Gerhard, 1965: Über das Vaterland, Boppard.

Oberndörfer, Dieter, 1995: Kulturelle Freiheit und Verfassungspatriotismus. Die Entwicklung vom Nationalstaat zum republikanischen Europa, in: Ansgar Klein (Hrsg.), Grundwerte in der Demokratie, Bonn (Schriftenreihe der Bundeszentrale für Politische Bildung).

Oberndörfer, Dieter, 1999: Integration or Segregation. On the way to the post-national republic?, in: Theodor Hanf (Hrsg.), Dealing with Difference. Religion, Ethnicity, and Politics: Comparing Cases and Concepts, Baden-Baden.

Pannier, Jörg, 1996: Das Vexierbild des Politischen. Dolf Sternberger als politischer Aristoteliker, Berlin.

Planert, Ute, 2004: Nation und Nationalismus in der deutschen Geschichte, in: APuZ, B 39, 32-38.

Radkau, Joachim, 2005: Weber. Die Leidenschaft des Denkens, München.

Ramm, Thilo, 2004: Die Deutschen - eine Nation?, in: APuZ, B 39, 32-38. 
Reinhard, Wolfgang, 2000: Geschichte der Staatsgewalt. Eine vergleichende Verfassungsgeschichte Europas von den Anfängen bis zur Gegenwart, München (2. durchgesehene Aufl.).

Rößler, Matthias, 2006: Patriotismus im vereinigten Europa, in: Die Politische Meinung, Nr. 435, Februar.

Schlie, Ulrich, 2004: „Behausung des Menschen in einer unbehausten Welt“. Nation und Europa in der deutschen Geschichte, in: APuZ, B 39, 25-31.

Schmitt, Carl, 1938: Der Leviathan in der Staatslehre des Thomas Hobbes, Hamburg.

Schmitt, Carl, 1963: Der Begriff des Politischen, Text von 1932 mit einem Vorwort und drei Corollarien, Berlin.

Scholz, Rupert, 2004: Deutschland in guter Verfassung?, Heidelberg.

Seibel, Wolfgang/Medick-Krakau, Monika/Münkler, Herfried/Greven, Michael Th. (Hrsg.), 1997: Demokratische Politik - Analyse und Theorie. Politikwissenschaft in der Bundesrepublik Deutschland, Opladen/Wiesbaden.

Sternberger, Dolf, 1949: Die deutsche Frage, in: Der Monat, Juni 1949.

Sternberger, Dolf, 1956: Lebende Verfassung. Studien über Koalition und Opposition. Meisenheim.

Sternberger, Dolf, ab 1977: Schriften, Frankfurt a. M.

Sternberger, Dolf, 1997: Das Wort „Politik“ und der Begriff des Politischen, in: Seibel u. a. $1997,97-105$.

Weber, Alfred, 1997-2003: Alfred-Weber-Gesamtausgabe (AWG). Hrsg. von Richard Bräu, Eberhard Demm, Hans G. Nutzinger und Walter Witzenmann, 10 Bde, Marburg. Wehler, Hans-Ulrich, 1988: Entsorgung der deutschen Vergangenheit? Ein polemischer Essay zum „Historikerstreit“, München.

Wehler, Hans-Ulrich, 2001: Nationalismus. Geschichte - Formen - Folgen, München.

Weidenfeld, Werner (Hrsg.), 1983: Die Identität der Deutschen, München.

Winkler, Heinrich August, 2000: Der lange Weg nach Westen. Bd. 2 Vom „Dritten Reich“ bis zur Wiedervereinigung, München.

Korrespondenzanschrift

Prof. Dr. Peter Molt

53604 Bad Honnef

Im Wingert 12

E-Mail:pmolt@t-online.de 